Page 1 of 16

\title{
Technological, Organisational and Environmental Drivers for Enterprise Systems Upgrade
}

\begin{abstract}
Purpose - Enterprise Systems upgrade is a complex phenomenon, yet it is possible to reduce the complexity, through understanding the upgrade drivers. This paper investigates the various upgrade drivers, to provide a detailed understanding of the factors driving upgrade decisions.

Design/methodology/approach - This research is grounded in a qualitative survey design. It utilises a web-based survey questionnaire and semi-structured interviews to collect data from 41 respondents representing 23 large organisations. The data was qualitatively analysed and coded to identify the various drivers and their influence on ES upgrade decisions.

Findings - Our results suggest that the upgrade decisions are dependent on establishing the need to upgrade, which is influenced by various drivers and stakeholders interests. Also, our findings suggest that organisations would only opt to upgrade when benefits are aligned with the upgrade and when the decision makes business sense.
\end{abstract}

Research limitations/implications - In this paper, we propose that there is a relationship between the upgrade drivers and the upgrade strategy. However, qualitative studies can only formulate logical generalisations. Hence, future research could explore these associations through a quantitative study to provide probabilistic generalisation, which offers either similar or conflicting arguments applicable to ES upgrade phenomenon.

Originality/value - This paper provides an alternative classification of upgrade drivers and conceptualises an association between upgrade drivers and the upgrade strategy, which in turn facilitates minimising disruptions and upgrade risks.

Keywords - Enterprise Systems, ES upgrade, Upgrade Drivers, Systems Upgrade, Qualitative Survey.

Paper type - Research paper 


\section{Introduction}

Enterprise systems (ES) upgrade is a continuous process in which organisations can take advantage of new, features and functionality that result in performance improvement, reduction in maintenance effort, and increased the capability to re-examine and automate business processes (Leyh \& Muschick, 2013). However, few organisations opt to upgrade their systems in a timely manner, Dempsey et al. (2013) suggest that could be associated with the organisation need to understand the benefits and evaluate the reliability and stability of the new version. This hesitation implies that organisations utilise outdated systems and risk losing continued technical support and may lead to increased operational overheads and performance bottlenecks. On the other hand, $\mathrm{Ng} \&$ Wang (2014) suggest that upgrading is a complex undertaking with a tendency of disrupting operations and running over-budget. The complexity is not eased by the fact that upgrades are recurring throughout the system's lifespan, at least once every two years (Zhao, 2007), which normally result in huge investment costs (Dempsey et al., 2013).

To date research on ES upgrade offered practical guidance for managing and supporting upgrade projects, with several studies offering valuable insights into upgrade factors. However, most of these studies focus on Enterprise Resource Planning ERP systems or a single system from the one vendor. Hence, there are several calls (see Claybaugh, 2010) for more research to explore other upgrade drivers or possibly examine if the upgrade drivers differ between vendors and /or systems. This implies that most of the existing studies are offering a fragmented view on whether similar drivers would influence upgrade decisions in the context of the whole ES landscape. Furthermore Paradonsaree et al. (2014) and Scheckenbach et al. (2014) suggests that research on upgrades is scarce. Hence, this paper investigates ES upgrades focusing on the drivers, to contribute new insights by addressing the following question: what drivers influence organisations to upgrade their systems, irrespective of the type of system within the ES landscape? It is anticipated that through answering this research question, it would encourage organisations to gain better insights of ES upgrade to understand when to take advantage of upgrades to support strategic plans and improve overall business performance while minimising disruptions and upgrade risks.

This paper is organised as follows; the second section provides a general background and overview of ES upgrade and discusses some of the findings from earlier studies. The third section outlines the methodology adopted in this study. The fourth section presents and discusses the findings and their implication on ES upgrade and draws relevant conclusions by relating these findings to the existing body of knowledge.

\section{ES Upgrade Overview}

ES has been interchangeably referred to as ERP. However, Davenport et al. (2004) suggest that ES and ERP are different. In fact, it can be argued that ES constitute a variety of systems including ERP, Customer Relationship Management (CRM), Supply Chain Management (SCM), and so forth to provide a complete overhaul of the transactions processing systems landscape (Markus \& Tanis, 2000; Shang \& Seddon, 2002). Ward et al. (2005) substantiate this explanation and describe ES as a comprehensive, configurable, and integrated suite of systems and information resources, which support organisational-wide operational and management processes. Thus, in this paper, we adopt the definition offered by Ward et al. (2005) and suggest that the suite of systems within an ES enable integration, collaboration, interaction, and support the organisation's processing needs.

According to the market survey results by Panorama (2014) cited by Ng \& Wang (2014), very few organisations tend to realise the full potential of their ES. According to Voulgaris et al. (2014) the actual ES value becomes visible and realised after the system 'go-live', a period referred to as a post-implementation phase. Several stages have been proposed as part of the post-implementation phase to support organisations to manage their systems effectively and efficiently. For example, the ES life cycle definition from Motiwalla \& Thompson (2009) offers four stages that are: stabilisation, backlog, new module and major upgrade as part of the post-implementation phase. The backlog stage deals with modification development, evaluating new requirements and processes to support business needs. The new module stage extends the implemented system with additional capabilities to support the existing processes and improvements in performance. The major upgrade stage focuses on extending and expanding the existing systems depending on business needs and keeping pace with the vendor's version release cycle. Based on this definition by Motiwalla \& Thompson (2009) this paper focuses on the main upgrades and refers to it as an upgrade. 
Upgrading is an important aspect in the systems lifespan that ensures continuous improvement and stability of the system's (Hecht et al., 2011). Vaucouleur (2009) defines ES upgrading as a process that intends to expand the existing system's core capabilities by improving functionality and taking advantage of new technology features, offered in a new version. $\mathrm{Ng}$ (2011) defines upgrading as replacing the existing version entirely or partly with a newer version from the same vendor or different vendor. Both these definitions suggest that upgrade results in functionality improvement when compared to the currently installed version. It can also be stated that there are two upgrade dimensions: version-to-version upgrade and system-to-system upgrade. Version-to-version upgrade implies that the currently installed system is replaced with a newer version of the same system from the same vendor. While system-to-system upgrade means that, the currently installed version is traded with another system altogether possibly from a different provider. According to the explanation from Seibel et al. (2006) the frequent release of new versions, it is possible that organisations opt to undertake version-to-version instead of system-tosystem upgrade, as they are familiar with the system capabilities. Therefore, we position our study as an investigation of version-to-version upgrade drivers.

Although major ES vendors offer strategies, methodologies and best practices to manage and support upgrades, many organisations employ their informal strategies when contemplating upgrading to the latest ES version. Therefore, the fundamental questions to ask during upgrade decision-making is when to upgrade and this is usually influenced by 'availability of a suitable version', 'the customer's need for upgrade' and 'economics' as specified by Kankaanpää \& Pekkola (2010). It is understood that several drivers (Table 1) influence the customer's need to upgrade.

Table 1: Factors influencing upgrade decisions

\begin{tabular}{|c|c|c|c|c|c|c|c|}
\hline \multirow[b]{2}{*}{ Reasons for upgrading } & \multicolumn{7}{|c|}{ Research Articles } \\
\hline & 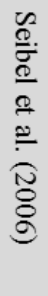 & 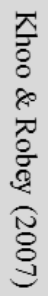 & 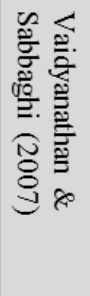 & 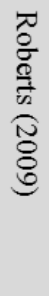 & 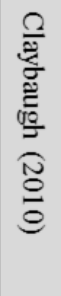 & 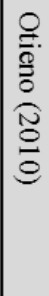 & 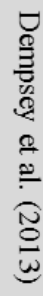 \\
\hline Continuousvendor support & $\mathrm{x}$ & $\mathrm{x}$ & $\mathrm{x}$ & $\mathrm{x}$ & $\mathrm{x}$ & $\mathrm{x}$ & $\mathrm{x}$ \\
\hline Technology advancements & $\mathrm{x}$ & $\mathrm{x}$ & $\mathrm{x}$ & & $\mathrm{x}$ & $\mathrm{x}$ & $\mathrm{x}$ \\
\hline Technology obsoleteness & $\mathrm{x}$ & & & $\mathrm{x}$ & & & \\
\hline Maintenance cost & & $\mathrm{x}$ & $\mathrm{x}$ & & $\mathrm{x}$ & $\mathrm{x}$ & $\mathrm{x}$ \\
\hline Improve usability & & $\mathrm{x}$ & $\mathrm{x}$ & $\mathrm{x}$ & & $\mathrm{x}$ & $\mathrm{x}$ \\
\hline Standardise functionality & $\mathrm{x}$ & $\mathrm{x}$ & & & $\mathrm{x}$ & $\mathrm{x}$ & $\mathrm{x}$ \\
\hline Improve decisions capabilities & $\mathrm{x}$ & & & $\mathrm{x}$ & & & \\
\hline Benefits realisation & $\mathrm{x}$ & $\mathrm{x}$ & $\mathrm{x}$ & & $\mathrm{x}$ & & $\mathrm{x}$ \\
\hline Improve external collaboration & & & $\mathrm{x}$ & $\mathrm{x}$ & & & \\
\hline Gain competitive advantage & & & & & & & $\mathrm{x}$ \\
\hline Processes consolidation & $\mathrm{x}$ & $\mathrm{x}$ & $\mathrm{x}$ & & $\mathrm{x}$ & $\mathrm{x}$ & $\mathrm{x}$ \\
\hline Legislation compliance & $\mathrm{x}$ & $\mathrm{x}$ & & $\mathrm{x}$ & $\mathrm{x}$ & $\mathrm{x}$ & $\mathrm{x}$ \\
\hline Integration of systems & $\mathrm{x}$ & $\mathrm{x}$ & $\mathrm{x}$ & $\mathrm{x}$ & $\mathrm{x}$ & $\mathrm{x}$ & \\
\hline Adapt new functionality & $\mathrm{x}$ & $\mathrm{x}$ & & $\mathrm{x}$ & $\mathrm{x}$ & $\mathrm{x}$ & $\mathrm{x}$ \\
\hline Management of modification & $\mathrm{x}$ & $\mathrm{x}$ & & $\mathrm{x}$ & $\mathrm{x}$ & $\mathrm{x}$ & $\mathrm{x}$ \\
\hline Automation & & $\mathrm{x}$ & & & $\mathrm{x}$ & $\mathrm{x}$ & \\
\hline Improve ways of operating & $\mathrm{x}$ & & $\mathrm{x}$ & $\mathrm{x}$ & & $\mathrm{x}$ & \\
\hline Attain better scalability & & & $\mathrm{x}$ & & $\mathrm{x}$ & $\mathrm{x}$ & $\mathrm{x}$ \\
\hline Restructure business processes & & $\mathrm{x}$ & $\mathrm{x}$ & & $\mathrm{x}$ & & $\mathrm{x}$ \\
\hline Increase performance & $\mathrm{x}$ & & $\mathrm{x}$ & & & $\mathrm{x}$ & $\mathrm{x}$ \\
\hline
\end{tabular}


influence the organisation to upgrade their ES, such as new functionality, business needs, and continuous vendor support. The inhibiting factors cause the organisation not to consider upgrading their systems; this includes costs and availability of resources. Whereas Claybaugh (2010) identifies drivers from existing IS literature and classifies them into three contexts, that is technological, organisational, and environmental. Based on responses from 190 experts, Claybaugh analyses the influence of these factors on the decision to upgrade. However, Claybaugh (2010) only focuses on a single vendor 'SAP' and a single system 'ERP'. Since each system within the ES landscape is implemented for a specific purpose, there is a huge possibility that the drivers that influence upgrade decisions can be different between systems and vendors. This could be the reason Claybaugh (2010) suggested that further research is required to explore factors that influence upgrade of other systems from same or different vendors. Additionally, generic strategies could be established, when organisations understand what drivers influence upgrading their entire ES landscape. Hence, this study attempts to understand and identify what motivates organisations to upgrade their current ES version, with the aim to identify common drivers within the ES landscape. Therefore, the outcome of this study would either extend the drivers proposed by Claybaugh (2010) and (or) provide some indication if similar drivers are influencing upgrade decision across the entire ES landscape.

\subsection{ES Upgrade drivers classification}

ES upgrade can be considered as an innovation due to the following reasons: Firstly, ES upgrade introduces changes to the existing business processes and implementation of new functionalities (Khoo \& Robey, 2007). Secondly upgrading expands core system capabilities by taking advantage of new technology features (Vaucouleur, 2009). Thirdly, upgrading ensures that the system is stable, operates efficiently, and can be expanded according to the organisation's needs (Hecht et al., 2011). In comparison to the Information Systems (IS) Innovation taxonomy by Swanson (1994), it can be reasoned that upgrading enhances the efficiency of IS tasks, improves administrative functions and enriches the features embedded in the core systems. As a result, it improves productivity and systems performance, minimises maintenance efforts, and increases competitiveness. Tornatzky \& Fleischer (1990) propose that the decision to adopt an innovation is influenced by external and internal factors, including the characteristics of the technology. Likewise, ES upgrade decisions are influenced by various internal and external drivers.

Though T-O-E framework has been mainly used to study the adoption of new technology innovations in organisations, Claybaugh (2010) adopts this framework to study ERP upgrades. Clayburg suggests that is will allow understanding factors affecting upgrade decisions. since organisations are at different assimilation stages, which is also suggested by Claybaugh et al. (2015). Also, Oliveira \& Martins (2011) suggests that the T-O-E framework has an established theoretical base and consistent empirical support for studying the adoption of innovation. Based on this context, we adopt the T-O-E framework, as an investigative lens for analysing ES upgrade drivers. As a result, these drivers were classified into three contexts: technology, organisation and environment. The technology context represents existing and new technologies relevant to the organisation, including their benefits, compatibility, and complexity (Lian et al., 2014). Organisational context describes the internal measures such as scope, size, managerial support, and availability of resources. Environmental context refers to the field in which the organisation operates; this includes elements such as government legislation and vendors' support. The categorisation of the drivers differs from the T-O-E framework, however, according to Tornatzky \& Fleischer (1990) specific categorisations may vary across different studies since the characteristics are subjective.

\subsubsection{Internal (technology) factors}

These drivers describe both the internal and external technologies advancements and their benefits to the organisation; however, what one organisation perceives as a benefit is not always reciprocated in another organisation (Claybaugh, 2010). Markus \& Tanis (2000) suggest that it is possible for two organisations to achieve the same benefit but gain different value from the benefit. The benefits for upgrading are obtained by comparing the new version against the existing version to gauge the usefulness and contribution of both versions ( $\mathrm{Ng}, 2011)$. The new version value materialises from its offering of new functionality, improved business process and technologies (Dempsey et al., 2013). Thus, organisations are more likely to upgrade when the benefits are known; that is the relative advantage of upgrading. Another category identified is compatibility; signifying the degree in which the new technology can be adopted without causing disruptions to the existing systems and its supporting 
infrastructure. Given that, new technologies are made available with latest versions; it is possible for disruptions to occur. According to Whang et al. (2003, p.1035), it is common for the new version to introduce changes, which affect the operating system and database system 'due to the higher version requirements'. This implies that it is important to consider hardware and supporting systems stability to accommodate the changes proposed by the new version. Another issue to consider when upgrading is the compatibility of the changes on the existing version's functionality or prior modifications implemented to the system and on inter-organisation systems. For example to remain competitive, an organisation integrates their ES with their supplier systems (Vaidyanathan \& Sabbaghi, 2007), which triggers the need to ensure stability and reliability of the systems when upgrading for the systems to operate smoothly. Overcoming compatibility is regarded as one of the reasons organisations opt to upgrade their systems, particularly when there are inter-organisational systems. Beatty \& Williams (2006) posit that this is one of the main challenges during the upgrade and consumes most of the project time and effort.

\subsubsection{Internal (organisation) factors}

One of the essential organisational factors is access to relevant information, which supports making decisions and improves productivity (Beheshti \& Beheshti, 2010). Important information in this context represents accurate, timely, and pertinent information that facilitates making decisions with ease. Another is to leverage ES to gain a competitive advantage by improving productivity and increasing financial performance through aligning business strategies with functionality ( $\mathrm{Ng}$ et al., 2003; Nicolaou \& Bhattacharya, 2006). Alignment of the system can be achieved through expanding the existing systems' capabilities through either modifying the system or implementing new features. According to Otieno (2010), the aligning of the system's functionality to organisation strategies could be accomplished by upgrading to a newer version. Normally, this results in business transformations, which ensure that the organisation adapts to the changing economic and market conditions. Worrell (2008) suggest that to support the transformations, the organisation requires eliminating redundant processes and re-engineering some of the processes or the implementation of new business processes. Thus, considering and planning for alignment may result in the organisation upgrading their system to take advantage of the new version features, to achieve existing and future goals that define the strategic direction of the organisation.

Beatty \& Williams (2006) and Olson \& Zhao (2007) stress the importance of management in influencing upgrade projects success. Thus, we consider that management support plays a major role in upgrade decisions. Another aspect is upgraded costs, which represent significant influence upgrade decisions. According to Swanton (2004), upgrade costs are almost " $50 \%$ of the original software licensing fee and $20 \%$ of the initial implementation cost per user - $£ 5.2 \mathrm{~m}$ for a 5,000-user system”. Likewise, Otieno (2010) suggests that upgrading costs ranges between $20 \%$ and $30 \%$, while $\mathrm{Ng}$ et al. (2003) estimate it ranges between $25-33 \%$ of the initial implementation cost. Hence, matured, upgrade costs remain a consistent factor that has always been considering as an ES upgrade inhibitor.

\subsubsection{External (Environment) factors}

These external factors define conditions that give the organisation little choice but to upgrade their systems. Mostly these factors would be initiated by different external stakeholders, such as vendors, partners, consultants, and legal entities. For example, the various versions release cycles introduced by vendors creates a dilemma of when it is appropriate to upgrade. Since on one hand, vendors provide organisations with the flexibility of not frequently upgrading, as they support multiple versions (Khoo \& Robey, 2007). Hence, vendors have a significant role in influencing upgrades through offering technological improvements and new features with each version release. On the other hand, vendors use high license fees and support pricing schemes for older versions as a technique to encourage organisations to upgrade their systems (Sawyer, 2000). Other external factors can be regarded as compliance with legislative changes and regulations since organisation opt to upgrade to fulfil government regulations such as changes in taxation. Additionally, organisations that operate in highly regulated environments such as education institutes and banking have to follow directives and regulations set by centrally governed agencies or governmental bodies (Khoo \& Robey, 2007; Ng \& Wang, 2014). In the context of environmental factors, the literature portrays a mixed reaction on the significance of these factors in influencing upgrade decisions. For example, Otieno (2010) suggests that business needs which include the requirement for new functionality and automating processes have higher priority when compared to environmental factors. Claybaugh et al. (2015) have demonstrated that there is a mutual degree of influence from organisational and environmental factors on upgrade decisions. Thus, it is important to establish the extent of environmental factors on upgrade decisions. 


\subsection{ES Upgrades strategies}

According to Dempsey et al. (2013) and (Ref) ${ }^{1}$ organisations can undertake either a technical or functional upgrade or a combination of both as their upgrade strategy. Technical upgrade necessitates moving the existing system to a new version of the latest technology platform, so as to leverage latest technology features and to align the systems within the product life cycle. This implies that a technical upgrade is independent of a functional upgrade and concentrates mostly on changes to the technology aspects of the system such as the system architecture (Dempsey et al., 2013). Undertaking a technical upgrade involves analysing the structure of data dictionary objects and evaluating the individual coding areas to confirm that the changes do not disturb the existing system (Beatty \& Williams, 2006). Whereas, functional upgrade mainly concentrates on functionality extension and optimising business processes based on the organisation's business needs. This may also involve consolidation of different systems, to provide better agility and flexibility to support the integrated systems. Hence during functional upgrades, the generic functionality offered in the new version will be implemented, with the aim of optimising business processes, which may result in re-applying the modifications and re-engineering existing business process (Riedel, 2009). However, there are instances both technical and functional upgrade are required. For example, a technical upgrade will be undertaken first to ensure the underlying system's platform is up-to-date and is capable of accommodating the changes to be introduced by the functional upgrade. Although some studies (Dempsey et al., 2013; Khoo \& Robey, 2007; Zhao, 2007) make reference to upgrade strategies, there is a limited explanation on how organisations' decide to undertake a particular strategy. Each upgrade strategy attempts to achieve a particular outcome, hence, it possible that the upgrade drivers play a role in influencing the selection, this association between upgrade drivers and upgrade strategy is theorised in Figure 1. Also, based on the drivers identified from the literature and the analytical lens, Figure 1 is used to guide data analysis, which compares the theoretical constructs from this study to previous studies to draw conclusions from this study.

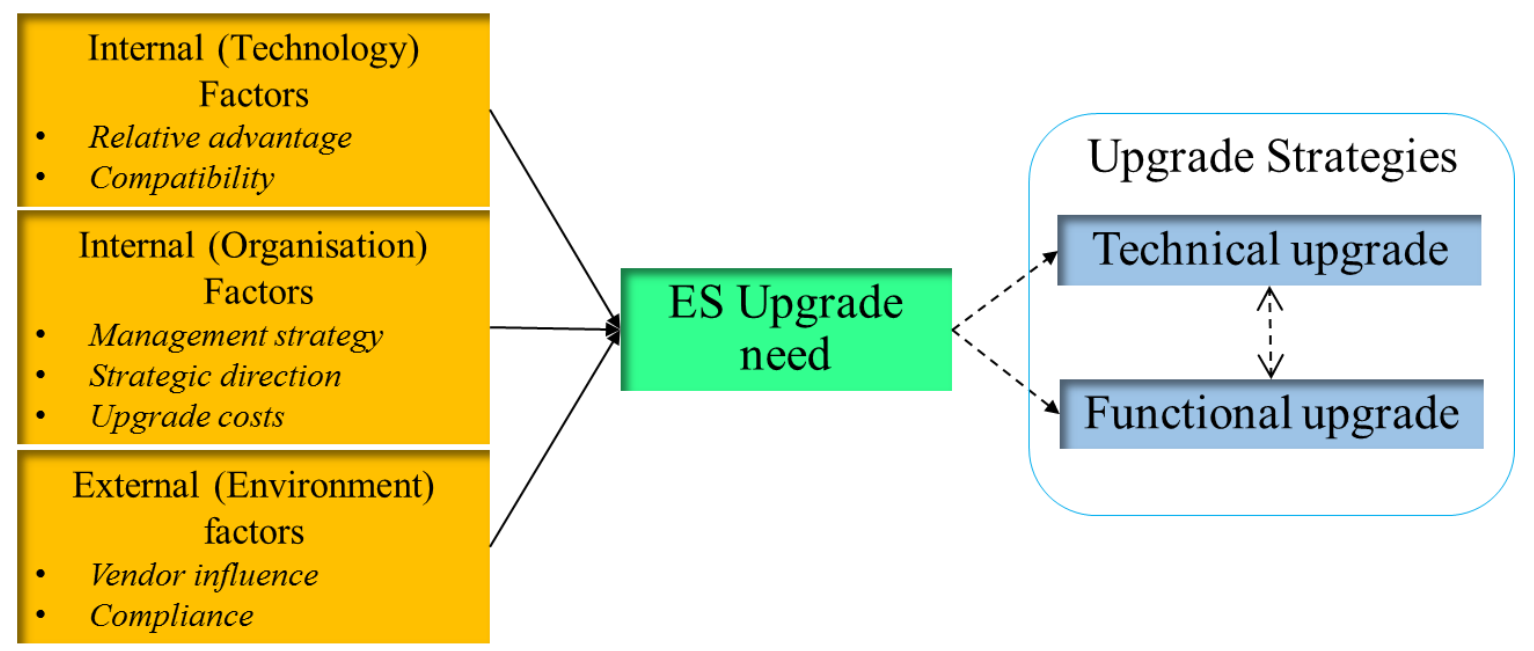

Figure 1: Research model: The potential association between upgrade drivers and upgrade strategies

\section{Methodology}

The use of surveys has been widely accepted in IS research (Oates, 2006; Pinsonneault \& Kraemer, 1993); however, it is usually associated with quantitative research (Creswell, 2009). Contrary to this belief, Fink (2003) and Jansen (2010) argue that a survey is a viable approach when conducting qualitative research and explain that the purpose is to study the diversity and depth within the research questions. Thus, from a methodological perspective qualitative survey allows the cross-examination of multiple respondents. Hence, this research follows a qualitative survey design. There are several reasons for adopting qualitative survey. First, to address the research questions, there was a need to attain realistic information from respondents who were involved in ES upgrade projects. According to Oates (2006) using a survey approach allows the researcher to engage and collect the same kind of data from a cross-sectional sample of the respondents. In turn, the researcher gathered upgrade experiences from multiple respondents, to establish common and diverse views on the factors influencing upgrade decisions.

\footnotetext{
${ }^{1}$ Reference has been removed, in order to preserve the authors anonymity
} 
Second, there was a necessity to associate information obtained from previous studies, to establish if the upgrade drivers are applicable across different systems. Hence, the use of qualitative survey facilitated exploring ES upgrades dimensions in order to offer insights into complex issues based on gathering realistic information from respondents. Such rich descriptive insights that explain the factors influencing ES upgrades are subjective to the people involved in the process hence requires an approach that can derive meaning and relationships to gather a detailed understanding (Denzin \& Lincoln, 2011). Figure 2 outlines the different data collection techniques and the data analysis approach adopted in this study.

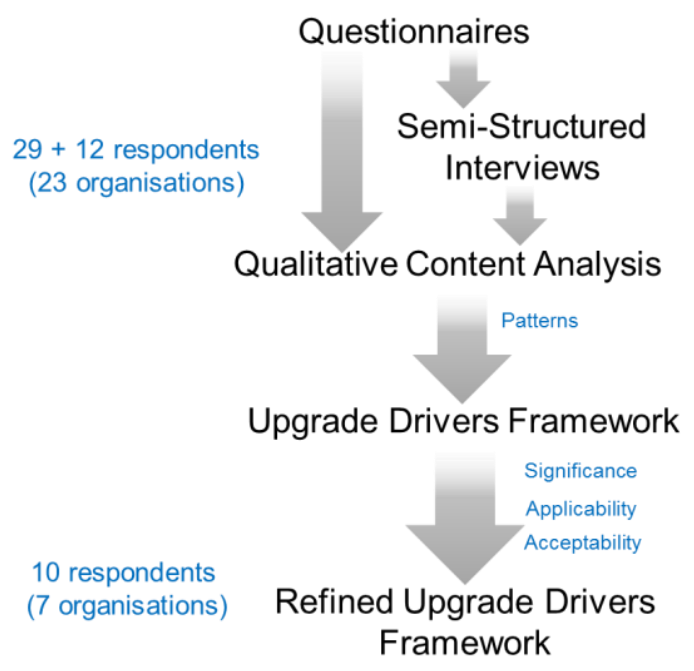

Figure 2: The qualitative survey research design

\subsection{Data Collection}

Two data collection techniques were utilised in this study to complement the deficiencies and biases that may arise when using a single method (Creswell, 2009). First, web-based questionnaires were used, to establish respondents' attitudes and experiences along with identifying the upgrade processes practised in their organisations along with the drivers influencing the decisions to upgrade. According to Kaplan \& Maxwell (2005), questionnaires (including web-based) could be utilised as one of the main data collection sources in the qualitative survey. However, the survey instrument should include open-ended questions. In this study, the survey instrument included both open-ended and close-ended questions. The closed-ended questions asked the respondents to indicate their level of agreement or disagreement based on a five-point Likert scale and yes or no answer option. Mostly this kind of questions was utilised to capture if the factors identified in the literature (Table 1) applied to the entire ES upgrade landscape. The open-ended questions allowed probing for more details about the upgrade drivers by encouraging the participants to provide in-depth descriptive accounts of their experiences on ES upgrade within their organisations.

Second, semi-structured interviews were utilised as another data collection technique. Semi-structured interviews offer a flexible approach to explore complex issues and gain rich, detailed insights based on people experiences and knowledge of the ES upgrade processes. Also, semi-structured interviews allow engaging with respondents who are regularly involved in the process under study (Silverman, 2005). Hence gathering the accounts of people that are involved in upgrade projects could provide in-depth information, which cannot be captured using questionnaire. Also, it can assist to overcome some of the criticisms of using web-based questionnaire, such as Buchanan (2000) points out issues with anonymity and repeat responders when using web-based questionnaire.

\subsection{Respondent Selection}

Snowballing and purposeful sampling were utilised to recruit respondents for the study. Firstly, purposeful sampling was used to request access to SAP and Oracle UK user group members. Both user groups represented organisations from UK and Ireland, which use systems from SAP, Oracle, JD Edwards, PeopleSoft, or Primavera. The administrators from both user groups offered to circulate our request in their monthly newsletters. Secondly, a snowballing technique was used to search for the respondents who may not be part of these groups, as they could offer a different upgrading experience. The approach involved manual searching LinkedIn® professional 
networking services for respondents based on the description provided in their profiles and location (UK \& Ireland). Then an email was sent out inviting them to participate in the study and politely requesting them to forward the message to their contacts with similar experience. For the interviews, the respondents were selected based on the suggestion from Olson \& Zhao (2007), who explained that upgrade is a continuous process recurring at least once every three years. Hence, the respondents level of experience was set at 6 or more years since these respondents would have been involved in more than one upgrade project.

\subsection{Data Analysis}

8 Qualitative content analysis principles guided the overall data analysis of this study, this implies the web-based the data from different respondents representing their respective organisations. As a result, various observations and trends could be categorised in respect to the drivers, upgrade process and decisions organisation undertake when considering upgrades. Thus, for this study, the unit of analysis was organisations, as the main aim of the study was to explore the factors influencing the organisation to upgrade their ES. The data was collected from respondents whose organisations either have recently upgraded or are in the process of upgrading or planning to upgrade in the next few months. According to Beatty \& Williams (2006), the upgrade projects encompasses different stakeholders, representing the functional and technical aspects of the system and management, who are mostly driven by various motives. Thus, it was opted during the web-based questionnaire to target at least two respondents from the same organisation to cover both the technical or functional perspectives.

The data from both data collection techniques allowed gathering detail descriptions of factors influencing organisations to upgrade their systems, along with the upgrade process. As, part of the analysis, the following three steps were followed: preparing the data, systematic coding, and drawing conclusions. Preparing the data involved studying the data as a whole to get a broader picture of how it reflected the research question. This involved summarising the concepts to understand the commonality between the data. Systematic coding utilised descriptive, interpretative, and pattern codes based on Miles \& Huberman (1994) code classification. This involved summarising and grouping the data into segments, which was then systematically labelled to give the segments meaning and to eliminate repetition. Next, any significant relationships emerging from the segments were acknowledged, in order to formulate a high-level analytical content with the intention of deriving the theoretical attributes. The systematic coding for the interviews and open-ended questions was done by two other independent coders, to ensure the reliability of the codes, segments, and patterns. Drawing conclusions involved exploring the identified segments to provide an explanation based on the theoretical propositions identified in relation to the research question and comparison to the contexts represented in Figure 1. This involved frequent visits to the notes and transcriptions to justify certain arguments versus the patterns.

Additionally, this study uses respondent validation, as a strategy to increase confidence and rigour in the findings. Respondent validation was applied in twofold: first, the interviews summary was sent to the interviewees to validate its contents for accuracy and if necessary amendments were made to the interview summaries. Once the review was verified, some of the details were posed as additional questions to the other interviewees, to get their opinions on the earlier descriptions of upgrade decision-making. Then a comparison between the answers was made to analyse the similarity of the different experiences. Second, the findings were evaluated by presenting to a diverse group of respondents with similar upgrade experience and knowledge, to assess the accuracy of the findings and its applicability and significance in influencing ES upgrades decision.

\section{Findings and Discussion}

The web-based questionnaire survey was conducted from May - September 2013, its responses were analysed before the semi-structured interviews. Although the web-based questionnaire offered detailed insights and a highlevel view of the upgrade processes, there were limitations regarding the depth of the explanation provided. For example, six respondents suggested their organisations were undertaking a technical upgrade only; another five suggested their organisation undertook functional upgrade only. The insights obtained from the analysis of the web-based questionnaires indicated that most of the drivers obtained from previous studies focusing on ERP or another subset of ES were applicable in influencing the upgrade of the whole ES landscape. Additionally, the data facilitated refining the initial thought process on the potential association between these drivers and upgrade strategies. However, most of the responses required an in-depth explanation, for each instance a different upgrade 
strategy was selected, because of several drivers but in each case no explanation was provided. Thus, it was difficult to draw any significant conclusion on the association between the upgrade drivers and upgrade strategy selection, even though the data indicated some level of association. Therefore, to attain a detailed explanation, some of the patterns from the questionnaire analysis were used to inform the design of the semi-structured interview, which was conducted from December 2013 to March 2014, this allowed to obtain an in-depth understanding along with establishing any associations between the upgrade drivers and upgrade strategy.

In total 41 respondents participated in both data collection techniques. 29 respondents out of the 41 completed the web-based questionnaires representing 18 different organisations. At this stage, most of the organisations were represented by two respondents. Also, 12 respondents participated in the semi-structured interviews representing 11 organisations. However, six respondents had also participated in the web-based questionnaire. Thus, only six new respondents participated in the interviews, representing an additional five organisations. In the interviews, all but one organisation were represented by a single respondent. The organisation that had two respondents was because the initial respondent believed that speaking to another member of the team that is involved in daily management of the systems could provide a more detailed explanation of the upgrade drivers and process. After interviewing 12 respondents, it was observed that a detailed subjective understanding and an appropriate level of diversity of the phenomena under investigation was obtained and no new dimension was being added, which according to Jansen (2010) could be argued that the study was reaching its saturation point. In conclusion, the total number of organisations involved in this study were 23 large organisation. Based on the explanation by Laukkanen et al. (2007) organisations with 250+ employees can be considered as large enterprises. Hence, the respondents of this study are considered to be from large organisations.

Most of the organisations were based in the UK and Ireland, but a few have international footprints, for example, 2 of the organisations were subsidiaries with their headquarters in Asia, while other 3 had offices across Europe. For those organisations based in UK and Ireland, the upgrade team was either located locally or from abroad. All respondents were at a minimum involved in one upgrade project and were actively engaged in the decision-making process. The respondents represented diversified roles and the majority of them have more than four years' experience in managing enterprise systems (Table $2 \& 3$ ). Some of the respondents (for example the Chief Financial Controller) were not directly involved with the day-to-day management of ES; however, they were part of the upgrade team representing the top management.

Table 2: Respondents' Roles

\begin{tabular}{|l|l|}
\hline \multicolumn{1}{|c|}{ Role } & Count \\
\hline Solution Architect & 7 \\
\hline Project Manager & 10 \\
\hline Systems Analyst & 4 \\
\hline Functional Lead & 9 \\
\hline Technical Lead & 7 \\
\hline Database Administrator & 4 \\
\hline Systems Administrator & 2 \\
\hline Chief Financial Controller & 1 \\
\hline Database Administrator & 1 \\
\hline Information Systems Manager & 1 \\
\hline
\end{tabular}

Table 3: Respondents' experience

\begin{tabular}{|l|c|}
\hline Experience & Count \\
\hline Less than 1 year & 0 \\
\hline 1 to 2 years & 1 \\
\hline 2 to 4 years & 5 \\
\hline 4 to 6 years & 4 \\
\hline 6 to 8 years & 14 \\
\hline More than 8 years & 17 \\
\hline
\end{tabular}

The pool of respondents consulted in this study offers a distinct selection of expertise and knowledge, which supports in-depth views on the upgrade process, an essential criterion to provide the necessary depth and richness required to address the research question. The study findings were presented and discussed with ten respondents from 7 different organisations, with the aim of gathering their opinions as an alternative mechanism to evaluate the interpretation of the findings. These respondents were involved in more than two ES upgrade projects and were actively engaged in the decision-making process. Also, as a mechanism to gauge the relevance of the drivers identified in respect of influencing the entire ES landscape upgrade decisions, the respondents were explicitly asked to suggest if such drivers applied to all of the systems within the ES landscape. 


\subsection{The upgrade drivers}

Organisations need to plan continuously and account for upgrade projects; however, the decision to upgrade is dependent on balancing the interaction of numerous technological, organisational, and environmental drivers, irrespective of the systems or vendors providing these systems. At least 25 of our respondents suggested that their organisation adopted a persuasive upgrade philosophy. According to Seibel et al. (2006) this is an undocumented management philosophy, but regarded a common strategy among management circles. This implies that the manner in which management strategies on upgrade influences the decision to upgrade; as they would not opt to upgrade immediately when a new version is released unless a justifiable need is established and (or) when upgrades can be associated with tangible \& intangible benefits. While some of the categories bear similarity to those proposed by Claybaugh (2010), the findings presented in this paper extend previous studies by providing additional categories that highlight the role of consultants, the different strategies adopted by the management and how compatibility issues influences upgrade decisions. Also, our findings suggest that upgrade drivers identified in previous studies are applicable when considering upgrading different systems within the ES landscape despite being from different vendors. In this paper, we classify the drivers influencing the decision to upgrade into three broad contexts and several categories, as summarised in Table 4.

Table 4: Upgrade drivers framework

\begin{tabular}{|c|c|c|}
\hline Contexts & Categories & Drivers \\
\hline \multirow[t]{4}{*}{ Technological } & \multirow[t]{2}{*}{ Relative advantage } & Improved usability and security \\
\hline & & New functionality \\
\hline & \multirow[t]{2}{*}{ Compatibility issues } & Stability \\
\hline & & Reliability \\
\hline \multirow[t]{14}{*}{ Organisational } & \multirow[t]{4}{*}{ Management strategy } & Management philosophy \\
\hline & & Continuous improvement \\
\hline & & Business continuity \\
\hline & & Automate existing business processes \\
\hline & \multirow[t]{6}{*}{ Strategic direction } & Merge systems across the organisation \\
\hline & & Restructure business processes \\
\hline & & Consolidate business processes \\
\hline & & Consistent system architecture \\
\hline & & Standardise functionality \\
\hline & & Reduce maintenance Costs \\
\hline & \multirow[t]{4}{*}{ Upgrade cost } & Licensing fees \\
\hline & & Infrastructure costs \\
\hline & & Testing and re-application of modifications costs \\
\hline & & Integration of different systems \\
\hline \multirow[t]{7}{*}{ Environmental } & \multirow[t]{2}{*}{ Vendor influence } & Attain continuous vendor support \\
\hline & & Leverage latest technology \\
\hline & \multirow[t]{3}{*}{ Compliance } & Comply with legislative guidelines \\
\hline & & Implement national standards \\
\hline & & Acceptable structure and mode of operating \\
\hline & \multirow[t]{2}{*}{ Consultants' influence } & Knowledge and experience \\
\hline & & Trusts and relationship \\
\hline
\end{tabular}

\subsubsection{Technological Context}

There are several advantages gained by upgrading, such as new features, and most of the respondents explained that their organisation opted to upgrade their systems as a mechanism to make use of the additional capabilities and features introduced by the new version. Also, two respondents suggested that they upgraded their systems and infrastructure as a result of new security features while other respondents explained that their organisations 
applied patches to their systems as a countermeasure to security concerns. It is acknowledged that security issues can lead to upgrades especially to the technology and infrastructure that supports the systems; which in turn could lead to upgrading the functional aspect of the system. Also, this study's findings suggested that through upgrading, the majority of the support personnel time and efforts were directed towards other critical process refinement and automation, thus allowing for transparency and accountability. The adopting of new functionality may provide flexibility however it may not be compatible with the existing version, hence making the system landscape unstable and increasing the chances of disruption. For example, two respondents suggested that there was a significant difference in the system objects offered in the new version, which can cause disruptions, particularly when not compatible with existing modifications. According to Beatty \& Williams (2006), such situation requires rigorous testing to guarantee that systems would be stable and reliable after the upgrade. Not surprisingly, all organisations in this study considered testing as one of the main activities during upgrades, and several different testing strategies are utilised to ensure systems operate as planned. This involves identifying and proposing mechanisms to address all the changes in the code and systems objects, to align these with the existing modifications. Depending on the level of effort required to address these issues, the organisation will assess if it is feasible to move ahead with the upgrade or select an upgrade strategy that is feasible to achieve.

\subsubsection{Organisational Context}

The categories in an organisational context are relative and perceived differently from one organisation to another. For example, high initial upgrade costs resulting from licensing fees, infrastructure, testing, and reapplication of modifications can lead to postponing the upgrade. On the other hand, reduction of overall operational, management and maintenance costs, can influence the organisation to upgrade. For example, five respondents claimed their organisations achieved operating cost reductions by aligning the systems to a consistent architecture and replacing modifications with standard system functionality when upgrading. However, there was no evidence presented to substantiate if any cost reduction occurred after upgrading. Thus, depending on the stakeholder's perception of the upgrade benefits, costs can either influence or hinder the decision to upgrade. Indicating an alternative perspective from previous studies (such as Dempsey et al., 2013; Khoo \& Robey, 2007; Otieno, 2010) who advocate that costs act as an inhibitor to upgrade decisions.

Also, similar to previous studies mentioned above, top management involvement is essential to ensure the success of an upgrade project. Even though, top management involvement is minimal, when the case for the upgrade was proposed by the top management and received the support it would ensure the project is assigned realistic timelines and resources. In 6 of the organisations where top management supported the project, both technical and functional upgrade were undertaken; though this, not a definite indication that top management support will result in both upgrade strategies since other drivers have to be taken into consideration. It can be reasoned that when top management is involved, there are minimum project scope trade-offs when compared to cases in which there was limited management support. Furthermore, similar to an explanation from Davenport et al. (2004) mergers and acquisitions are an on-going process in organisations as part of their strategic direction. These mergers resulted in frequent changes to the business structures and processes, which dictate the need to integrate and have consistent systems to support their business vision, objectives, and processes. This was a case with 1 of the organisations in this study that had to upgrade to be on a consistent system version, to be able to integrate and standardise their processes with the other company. Additionally, some organisations claimed that they opted to upgrade, in order to improve performance, and become more competitive.

\subsubsection{Environmental Context}

In regards to environmental context, this study supports the findings from Claybaugh (2010) and suggests that there is a need to concentrate equally on the external drivers, which differs from the argument raised by Otieno (2010) that business needs (i.e. organisational drivers) have higher priority. The possible explanation for this difference is organisations that rely on vendors for continuous support and maintenance would tend to upgrade their systems whenever a new version is available to gain continuous support. Similar to previous studies, the study's findings suggest vendors influence the decision to upgrade, for example by withdrawing support for older versions, organisations are given no choice but to upgrade their systems to maintain continuous support. As a result, five organisations tend to upgrade even when the new version does not offer any improvements or benefits to the organisation; this is mostly applicable to organisations that are depending on vendors for support. In addition, vendors tend to lock-in their customers, with limited support and high licencing and maintenance costs for older 
versions. For example, five organisation in our study opted not to upgrade their systems. As a result, they did not receive support in a timely fashion and had to pay high premiums to get support for their older versions. In regards to compliance, similar observations to Khoo \& Robey (2007) were drawn, that is organisations in controlled environments upgrade their systems to keep up with the regulations and policies. However, due to the frequency (at least once a year), these changes can be accomplished by simply patching certain rules-sets and attributes in the systems. Hence, contrasting the suggestions proposed by Kremers \& van Dissel (2000) who mentions compliance as a technical upgrade while in this case it is mostly regarded a routine upgrade to the functional aspects of the system.

9 Consultants' influence was a recurring theme, as most of the respondents suggested that their organisations call The perception is that consultants can provide detailed functionality descriptions in a manner that organisations can easily comprehend when compared to vendor documentation, press releases, and websites. Although consultants play a critical role in influencing upgrade decisions, the level of influence depends on how much confidence the organisations place on the consultants' knowledge and experience. The same consultants are utilised for many different projects, to minimise potential pitfalls, risks, and disruptions associated with upgrades, which results in trust and good working relationships. However, organisations normally exercise caution, when using consultants, in order not lose control of critical upgrade decisions.

\subsection{Upgrade Strategy Selection}

Based on the data gathered, we hypothetically suggest that it is possible the upgrade drivers influence the upgrade strategy selection i.e. undertake either a technical-, functional upgrade or both as shown in Figure 3. Given that this is a qualitative study, we acknowledge it is difficult to conclude with certainty that there is an association between upgrade drivers and upgrade strategies. However, the trend in the data indicated that some organisation is upgraded because of certain specific drivers, for example, organisations that only wanted to be within the vendor release cycle to attain continuous support would normally consider undertaking technical upgrade only.

\section{Upgrade Drivers}

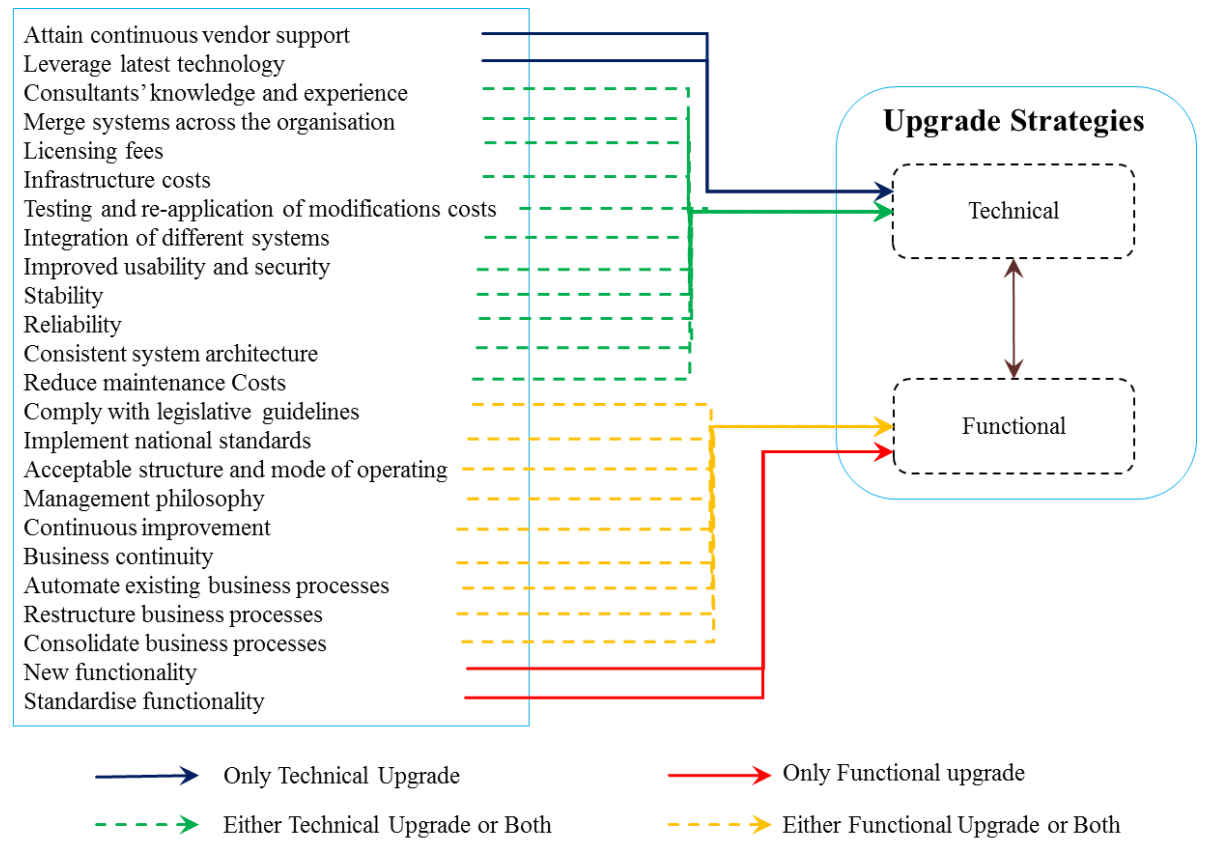

Figure 3: A conceptual association between upgrade drivers and upgrade strategy

Nevertheless, it is very rare for a single driver to influence an upgrade strategy. Thus, an upgrade strategy will be selected as a result of the collaboration between the different drivers. However when one or two drivers result in the selection of either a technical or functional upgrade, this can be regarded as a direct influence indicated by the blue and solid red lines in figure 3. While the dotted lines highlight the interaction of different drivers can result in undertaking either one of both upgrade strategies, the green colour indicates that technical upgrade would be 
upgraded strategy selected, but it may result in a functional upgrade. The yellow colour suggests that functional upgrade would be the ideal upgrade strategy, but it may also require a technical upgrade to be undertaken. For example, if the upgrade goal is to take advantage of the latest functionality to support the business users' requirements, then only a functional upgrade may be commissioned. However, if the underlying system's technical platform cannot support these changes, it creates a necessity for undertaking both technical upgrade and functional upgrade, to ensure the system can support the proposed functionality changes. This behaviour is considered as an indirect influence. This potential the relationship between the drivers and upgrade strategy selection can offer an explanation of why organisations prefer to undertake a certain upgrade strategy. However, in this study were are only proposing logical generalisation, and we recommend future research to explore this conceptual relationship suggested in this study and provide probabilistic generalisation, which could offer either similar or conflicting arguments applicable to ES upgrade strategy selection.

\section{Conclusions}

This paper has given an account and categorised the reasons for upgrading enterprise systems. From a theoretical position, this research supplements and extends previous studies on ES upgrades by demonstrating the applicability of earlier factors influencing upgrade decisions. From an organisational perspective, this study provides a detailed account of upgrade experiences from 23 organisations, providing insights and a broad understanding of the interplay between the different drivers and their role in selecting an upgrade strategy. Also, this research suggests there is a relationship between the upgrade strategy and upgrade drivers, which offers a logical strategy that can be followed when contemplating upgrade decisions to decide which upgrade strategy to select. As such, organisations could learn from the experiences of these 23 organisations, and devise an upgrade approach that minimises disruptions, risks, and allocating resources appropriately, along with reducing the complexity associated with upgrade projects.

Despite the small group of respondents involved in this research, the two data collection approaches allowed discovery of several upgrade drivers contributing to the growing body of literature on ES upgrade. However, as the majority of the respondents represent large organisations, the findings could be considered a context sensitive. Hence, only logical generalisations can be drawn. Therefore, further efforts to expand and extend the findings are required. Additionally, future studies could explore the full upgrade cycle to provide a detailed understanding of the dynamic nature of ES upgrade and identify strategies and mechanisms that can help to establish a balance between the needs of the stakeholders. 


\section{References}

Beatty, R.C. and Williams, C.D. (2006) ERP II: Best practices for successfully implementing an ERP upgrade. Communications of the ACM, 49(3), pp.105-109.

Beheshti, H.M. and Beheshti, C.M. (2010) Improving productivity and firm performance with enterprise resource planning. Enterprise Information Systems, 4(4), pp.445-472.

Claybaugh, C.C. (2010) Timing of Technology Upgrades: A Case of Enterprise Systems. PhD Thesis, University of Wisconsin - Milwaukee.

Claybaugh, C.C., Ramamurthy, K. and Haseman, W.D. (2015) Assimilation of enterprise technology upgrades: a factor-based study. Enterprise Information Systems, pp.1-34.

Creswell, J. (2009) Research design : qualitative, quantitative, and mixed methods approaches. 3rd ed. SAGE Publications, Los Angeles.

Davenport, T.H., Harris, J.G. and Cantrell, S. (2004) Enterprise systems and ongoing process change. Business Process Management Journal, 10, pp.16-26.

Dempsey, S., Vance, R. and Sheehan, L. (2013) Justification of An Upgrade of An Enterprise Resource Planning (ERP) System - The Accountant's Role Global Journal of Human Social Science, 13(1).

Denzin, N.K. and Lincoln, Y.S. (2011) Introduction: The Discipline and Practise of Qualitative Research. In Denzin, N. K. and Lincoln, Y. S. (eds.) The Sage handbook of qualitative research. 4th ed. SAGE Publications, Thousand Oaks.

Fink, A. (2003) The survey kit. 2nd ed. SAGE Publications, Thousand Oaks, California.

Hecht, S., Wittges, H. and Krcmar, H. (2011) IT capabilities in ERP maintenance - A review of the ERP post-implementation literature. In the proceedings of the 19th European Conference on Information Systems, AIS Electronic Library, Helsinki, Finland.

Jansen, H. (2010) The Logic of Qualitative Survey Research and its Position in the Field of Social Research Methods. Forum Qualitative Sozialforschung / Forum: Qualitative Social Research, 11(2).

Kankaanpää, I. and Pekkola, S. (2010) Timing the Information Systems Upgrade. In the proceedings of the 18th European Conference on Information Systems, pp.1545-1557, Department of Informatics, Pretoria, South Africa.

Kaplan, B. and Maxwell, J. (2005) Qualitative Research Methods for Evaluating Computer Information Systems. In Anderson, J. and Aydin, C. (eds.) Evaluating the Organizational Impact of Healthcare Information Systems. Springer, New York.

Khoo, H.M. and Robey, D. (2007) Deciding to upgrade packaged software: a comparative case study of motives, contingencies and dependencies. European Journal of Information Systems, 16(5), pp.555-567.

Kremers, M. and van Dissel, H. (2000) Enterprise resource planning: ERP system migrations. Communications of the ACM, 43(4), pp.53-56.

Laukkanen, S., Sarpola, S. and Hallikainen, P. (2007) Enterprise size matters: objectives and constraints of ERP adoption. Journal of Enterprise Information Management, 20(3), pp.319334.

Leyh, C. and Muschick, P. (2013) Critical Success Factors for ERP system upgrades - The Case of a German large-scale Enterprise. In the proceedings of the 19th Americas Conference on Information Systems, AIS Electronic Library, Chicago, USA.

Lian, J.-W., Yen, D.C. and Wang, Y.-T. (2014) An exploratory study to understand the critical factors affecting the decision to adopt cloud computing in Taiwan hospital. International Journal of Information Management, 34(1), pp.28-36.

Markus, M.L. and Tanis, C. (2000) The enterprise systems experience-from adoption to success. In Zmud, R. W. (ed.) Framing the domains of IT research: Glimpsing the future through the past. Pinnaflex Education Resources, Cincinnati, $\mathrm{OH}$.

Miles, M.B. and Huberman, M.A. (1994) Qualitative data analysis: an expanded sourcebook. 2nd ed. SAGE Publications, Thousand Oaks. 
Motiwalla, L.F. and Thompson, J. (2009) Enterprise systems for management. Pearson Prentice Hall, NJ.

Ng, C.S.-P. (2011) Enterprise Resource Planning (ERP) Upgrade Decision: Toward A Unified View. In the proceedings of the 7th Pacific Asia Conference on Information Systems, pp.1039-1054, AIS Electronic Library, Adelaide, Australia.

Ng, C.S.-P., Gable, G.G. and Chan, T. (2003) An ERP maintenance model. In the proceedings of the 36th Annual Hawaii International Conference on System Sciences, p.234, IEEE Computer Society, Hawaii, USA.

Ng, C.S.-P. and Wang, E. (2014) An Exploratory Study of the Emergent Theory for Enterprise Resource Planning Upgrade Decision. In the proceedings of the 25th Australasian Conference on Information Systems, ACIS, Auckland, New Zealand.

Nicolaou, A.I. and Bhattacharya, S. (2006) Organizational performance effects of ERP systems usage: The impact of post-implementation changes. International Journal of Accounting Information Systems, 7(1), pp.18-35.

Oates, B. (2006) Researching information systems and computing. SAGE, London.

Oliveira, T. and Martins, M.F. (2011) Literature Review of Information Technology Adoption Models at Firm Level. The Electronic Journal Information Systems Evaluation, 14(1), pp.110-121.

Olson, D.L. and Zhao, F. (2007) CIOs' perspectives of critical success factors in ERP upgrade projects. Enterprise Information Systems, 1(1), pp.129-138.

Otieno, J.O. (2010) Enterprise Resource Planning Systems Implementation and Upgrade. PhD Thesis, Middlesex University

Paradonsaree, R., Singh, M. and Gekara, V. (2014) Business Process Changes for ERP Upgrades: Impact on organizational capabilities and improvements In the proceedings of the 35th International Conference on Information Systems, http://aisel.aisnet.org/, Auckland, New Zeland.

Pinsonneault, A. and Kraemer, K.L. (1993) Survey Research Methodology in Management Information Systems: An Assessment. Journal of Management Information Systems, 10, pp.75-105.

Riedel, M. (2009) Managing SAP ERP 6.0 upgrade projects. Galileo Press, Bonn.

Sawyer, P. (2000) Packaged Software: Challenges for RE. Sixth International Workshop on Requirements Engineering: Foundations of Software Quality. Stockholm, Sweden, pp.137142 .

Scheckenbach, T., Zhao, F., Allard, E., Burke, J., Chiwaki, K. and Marlow, S. (2014) Issues of ERP Upgrade in Public Sectors: A Case Study. In Kurosu, M. (ed.) Human-Computer Interaction. Applications and Services. Springer International Publishing,

Seibel, J.S., Mazzuchi, T.A. and Sarkani, S. (2006) Same vendor, version-to-version upgrade decision support model for commercial off-the-shelf productivity applications. Systems Engineering, 9(4), pp.296-312.

Shang, S. and Seddon, P.B. (2002) Assessing and managing the benefits of enterprise systems: the business manager's perspective. Information Systems Journal, 12(4), pp.271-299.

Silverman, D. (2005) Doing qualitative research: a practical handbook. 2nd ed. SAGE Publications, London; Thousand Oaks, Calif.

Swanson, E.B. (1994) Information-Systems Innovation among Organizations. Management Science, 40(9), pp.1069-1092.

Tornatzky, L.G. and Fleischer, M. (1990) The processes of technological innovation. Lexington Books, Lexington, Mass.

Vaidyanathan, G. and Sabbaghi, A. (2007) Supply Chain Software: Customer decision framework and global customer perspective on software upgrade and intergration. Issues in Information Systems, 8(2), pp.412-417.

Vaucouleur, S. (2009) Customizable and Upgradable Enterprise Systems without the Crystal Ball Assumption. In the proceedings of the 13 International EDOC Enterprise Computing Conference, pp.203-212, IEEE computer Society, Auckland, New Zealand. 
Voulgaris, F., Lemonakis, C. and Papoutsakis, M. (2014) The impact of ERP systems on firm performance: the case of Greek enterprises. Global Business and Economics Review, 17(1), pp.112-129.

Ward, J., Hemingway, C. and Daniel, E. (2005) A framework for addressing the organisational issues of enterprise systems implementation. The Journal of Strategic Information Systems, 14(2), pp.97-119.

Whang, J., Lee, M. and Kim, K. (2003) A Case Study on the Successful Upgrade of ERP System. The 7th Pacific Asia Conference on Information Systems. Adelaide, Australia, pp.1030-1038.

Worrell, J.L. (2008) Running the ERP marathon: enhancing ERP- business fit in the postimplementation phase. PhD Thesis, Florida State University

Zhao, F. (2007) An empirical study of enterprise system upgrades. PhD Thesis, University of Nebraska.

\section{Acknowledgement}

This paper was presented at the $19^{\text {th }}$ Pacific Asia Conference on Information Systems, Singapore, 6 - 9 July 2015. 